\title{
An Analysis of Intracranial Aneurysms Presenting with Subarachnoid Haemorrhage in Manipal Teaching Hospital Pokhara
}

\author{
Karmacharya $\mathbf{B}^{1}$, Yogi $\mathbf{N}^{1}$ \\ ${ }^{1}$ Department of Neurosurgery, Manipal Teaching Hospital, Pokhara, Nepal \\ Received: November 10, 2017 \\ Accepted: February 10, 2018 \\ Published: June 30, 2018 \\ Cite this paper: \\ Karmacharya B, Yogi N. An Analysis of Intracranial Aneurysms Presenting with Subarachnoid Hemorrhage in Manipal \\ Teaching Hospital Pokhara. Nepalese Journal of Radiology 2018;8(11):20-24.http://dx.doi.org/10.3126/njr.v8i1.20451
}

\begin{abstract}
Introduction: Rupture of intracranial aneurysms is the most common cause for spontaneous subarachnoid hemorrhage. It is a devastating stroke with high morbidity and mortality. This study was done to determine the frequency, location and size of aneurysms in patients presenting with spontaneous subarachnoid hemorrhage.

Methods: This prospective cross sectional observational study was conducted in the Neurosurgery Unit of Manipal Teaching Hospital from January 2012 to June 2016. All patients who presented with spontaneous subarachnoid hemorrhage and had a positive angiography of brain were included in the study.
\end{abstract}

Results: There were 39 patients who had positive angiographic results. Male: female ratio was 1:2.25. Mean age was 55.79 years. Nine patients had more than one aneurysms. More than $50 \%$ of patients were of age group 50-70 years. Anterior circulation aneurysms were found in $90 \%$ of patients. Anterior communicating artery was the commonest location of aneurysms. Most of the aneurysms had neck size less than $4 \mathrm{~mm}$.

Conclusion: Anterior communicating artery aneurysm was the commonest location of ruptured aneurysms. $23.07 \%$ of patients had multiple aneurysms.

Key words: Anterior Cerebral Artery; Intracranial Aneurysm; Subarachnoid hemorrhage

\section{INTRODUCTION}

Subarachnoid hemorrhage (SAH) is bleeding into the subarachnoid space - the area between the arachnoid membrane and the pia mater surrounding the brain. ${ }^{1}$ Most common cause of subarachnoid hemorrhage is trauma. Non traumatic or spontaneous subarachnoid

Correspondence to: Dr Balgopal Karmacharya Department of Neurosurgery

Manipal Teaching Hospital

Pokhara, Nepal

Email: dr.balgopal@hotmail.com hemorrhage is due to rupture of aneurysms, arteriovenous malformations and other 
vascular anomalies. Classical presentation of ruptured aneurysm causing subarachnoid hemorrhage is thunderclap headache (a headache described as "like being kicked on the head" or the "worst headache ever' developing over seconds to minutes). ${ }^{2}$ However patients may have nausea, vomiting, seizures, neck pain, photophobia and focal cranial or motor deficit or may even present with coma. Clinical condition of patients with subarachnoid hemorrhage is classified according to Hunt and Hess grading ${ }^{3}$ and WFNS grading. ${ }^{4}$ Aneurysms may be detected incidentally as well. Rapid expansion of an aneurysm like posterior communicating artery aneurysm may present with third nerve palsy. Giant aneurysms with in situ thrombus may present with cerebral infarction due to thromboembolism.

Non contrast computed tomography is the investigation of choice for confirming the presence of subarachnoid hemorrhage. It detects subarachnoid hemorrhage in $98.7 \%$ patients within six hours of ictus. ${ }^{5}$ Lumbar puncture is mandatory if $\mathrm{CT}$ is negative but still clinical suspicion of subarachnoid hemorrhage is high. CSF studies show evidence of hemorrhage in $3 \%$ of people in whom CT is found normal. ${ }^{6}$ Fischer grade classifies the appearance of subarachnoid hemorrhage on CT scan. ${ }^{7}$ It has prognosis for development of cerebral vasospasm, one of the dreadful complications. After subarachnoid hemorrhage is confirmed, its source should be determined by doing CT angiography or digital subtraction angiography. This study was conducted to find out the frequency, location and size of aneurysms in patients presenting with spontaneous subarachnoid hemorrhage. The rationale was to find out the distribution of ruptured intracranial aneurysms in patients from this western part of Nepal.

\section{METHODS}

This observational cross sectional study was carried out in Manipal Teaching
Hospital Pokhara Nepal from January 2012 to June 2016. Patient population included patients who presented with subarachnoid hemorrhage. All patients with subarachnoid hemorrhage underwent CT angiography of brain on 16 slice multidetector CT scanner. Scan was taken from base of skull to vertex. In addition to axial source data, post processed multiplanar reformatted (MPR), maximum intensity projection (MIP) and $3 \mathrm{D}$ volume rendering (VR) images were evaluated for any aneurysms. Aneurysms morphology studied include location of aneurysm, number of aneurysm, neck size and length and breathe of the fundus. Only patients who had an aneurysm demonstrated on the CT angiography were taken for analysis.

\section{RESULTS}

There were 39 patients who had positive angiographic results. There were 12 males $(30.77 \%)$ and 27 females (69.23\%). Female: male ratio was $2.25: 1$. These patients harbored 50 aneurysms. Mean age was 55.79 years and ranged from 18 to 78 years. Age distribution of patients is given in Table 1 . Thirty patients $(76.92 \%)$ had single aneurysm, 7 patients $(17.95 \%)$ had two aneurysms and two patients $(5.13 \%)$ had three aneurysms. Forty five aneurysms (90\%) were in the anterior circulation and five aneurysms $(10 \%)$ were in the posterior circulation. Anterior communicating artery aneurysm was the most common site for aneurysms followed by middle cerebral artery aneurysm. Table 2 shows the aneurysm locations. Among patients who had more than one aneurysm, 2 patients were male and 7 were females. Thus multiple aneurysms were found in $23.08 \%$ of patients. Multiple aneurysm were found in $16.7 \%$ of male and $25.94 \%$ of females. Mean neck size was $3.75+/-1.78 \mathrm{~mm}$ and ranged from 1.3 to $10.3 \mathrm{~mm}$. Thirty five aneurysms (70\%) had neck size $<4 \mathrm{~mm}, 14$ aneurysms(28\%) had neck size $4-10 \mathrm{~mm}$ and 1 aneurysm $(2 \%)$ had neck size more than $10 \mathrm{~mm}$. 
Table 1: Age Distribution of Patients

\begin{tabular}{|l|l|l|}
\hline Age group & Number of patients & Percentage \\
\hline$<20$ yrs & 1 & 2.56 \\
\hline $20-30$ yrs & 0 & 0 \\
\hline $30-40$ yrs & 1 & 2.56 \\
\hline $40-50$ yrs & 10 & 25.64 \\
\hline $50-60$ yrs & 8 & 20.51 \\
\hline $60-70$ yrs & 14 & 35.89 \\
\hline $70-80$ yrs & 5 & 12.82 \\
\hline
\end{tabular}

Table 2: Location of Aneurysms

\begin{tabular}{|c|l|l|}
\hline Aneurysm location & Number & Percentage \\
\hline Anterior circulation & $\mathbf{4 5}$ & $\mathbf{9 0}$ \\
\hline Anterior communicating artery & 16 & 32 \\
\hline A2 segment & 3 & 6 \\
\hline Posterior communicating artery & 4 & 8 \\
\hline M1 segment & 11 & 22 \\
\hline M2 segment & 1 & 2 \\
\hline Anterior choroidal & 2 & 4 \\
\hline Internal carotid artery & 8 & 16 \\
\hline Posterior Circulation & $\mathbf{5}$ & \\
\hline V-J junction & 2 & 4 \\
\hline Basilar tip & 1 & 2 \\
\hline Posterior inferior cerebellar artery & 2 & 4 \\
\hline
\end{tabular}

\section{DISCUSSION}

Subarachnoid hemorrhage is mostly due to ruptured aneurysms. Spontaneous subarachnoid hemorrhage is one of the devastating conditions with associated 50$60 \%$ morbidity and mortality. Subarachnoid hemorrhage can be clinically diagnosed. Ottawa SAH rule had $100 \%$ sensitivity and $13.6 \%$ specificity in detecting $\mathrm{SAH}^{8}$

CT angiography of brain is increasingly used as the first diagnostic tool for detection of aneurysms in patients who present with subarachnoid hemorrhage. CT angiography can help determine the etiology of aneurysm hemorrhage and selecting treatment options. It has replaced digital subtraction angiography. CT angiography is noninvasive and widely available whereas digital subtraction angiography is invasive, not widely available and is associated with complications of stroke itself. However, CT angiography may have some limitations as primary diagnostic tool. In a study done by Bechan RS et al, sensitivity of CT angiography in detecting ruptured aneurysm was $0.88-0.91$ and accuracy was 0.88-.92. ${ }^{9}$ However in places like ours where DSA is not available, it is still the choice of investigation.

Devkota UP et al studied subarachnoid hemorrhage due to ruptured intracranial aneurysms. In his study, male: female ratio of patients 1:1.5. ${ }^{10}$ Mean age of patients was 43.2 years. Anterior communicating artery aneurysm were found in $41 \%$ patients. Multiple aneurysms were found in $10 \%$ and giant aneurysms in $8 \%$. 
Size of aneurysm is one of the most important prognostic factor for its rupture. In the study done by Jagadeesan $\mathrm{BD}$ et $\mathrm{al}^{11}$, ruptured aneurysms with small neck measuring $<3$ $\mathrm{mm}$ was $33.5 \%$ among single aneurysms and $24.6 \%$ among patients with multiple aneurysms. Similarly in the Cooperative Aneurysm Study ${ }^{12}$ of 1092 patients, median diameter of ruptured aneurysm was $7 \mathrm{~mm}$ with mean diameter of $8.2 \mathrm{~mm}$. In this study, 70\% of aneurysms were $<10 \mathrm{~mm}, 13 \%$ aneurysms were $<5 \mathrm{~mm}$. Middle cerebral aneurysms were the largest and anterior communicating artery aneurysms were the smallest.

In a study done in Finland by Korja $\mathrm{M}$ et al ${ }^{13}$ male: female ratio of 1993 patients with ruptured intracranial aneurysms was $1: 1.5$. Ninety percent of aneurysms were of the anterior circulation, $83 \%$ of all aneurysms of middle cerebral artery, anterior communicating artery, posterior communicating artery and pericallosal artery. Sixty eight percentage of aneurysms were $<10$ $\mathrm{mm}$. Multiple aneurysms were found in $30 \%$ patients. Multiple aneurysms were found in $17.72 \%$ of patients in a study done in Japan ${ }^{14}$ ,among male multiple aneurysms were found in $12.4 \%$ and among females in $20.2 \%$.

\section{CONCLUSION}

In the current study, as in other studies, anterior communicating artery was the commonest site of ruptured aneurysm causing spontaneous subarachnoid hemorrhage. Ruptured aneurysms were found more in females. More than $95 \%$ of aneurysms were small sized with neck diameter $<10 \mathrm{mms}$. Multiple aneurysms were found in $23 \%$ of patients.

\section{CONFLICT OF INTEREST}

None

\section{SOURCES OF FUNDING}

None

\section{REFERENCES}

1. Abraham MK, Chang WW. Subarachnoid Hemorrhage. Emerg Med Clin North Am 2016;34(4):901-916. https://doi.org/10.1016/j. emc.2016.06.011

2. Longmore M, Wilkinson IB,Turmezei T, Cheung CK. Oxford Handbook of Clinical Medicine.7th edition. Oxford:Oxford University Press 2007:p841.

3. Hunt WE, Hess RM. Surgical risk as related to time of intervention in the repair of intracranial aneurysms. J. Neurosurg 1968;28(1):14-20. https://doi.org/10.3171/ jns.1968.28.1.0014

4. Teasdale GM, Drake CG, Hunt W et al. A universal subarachnoid hemorrhage scale: report of a committee of the World Federation of Neurosurgical Societies. $J$ Neurol Neurosurg Psychiatry 1988;51(11):1457. https://doi.org/10.1136/jnnp.51.11.1457

5. Dubosh NM, Bellolio MF, Rabinstein AA, Edlow JA. Sensitivity of early brain computed tomography to exclude aneurysmal subarachnoid hemorrhage: a systematic review and metaanalysis. Stroke 2016;47(3):750-755. ht tps://doi .org/10.1161/ STROKEAHA.115.011386

6. Van GJ, Kerr RS, Rinkel GJ. Subarachnoid haemorrhage. The Lancet 2007;369(9558):306-318. https://doi.org/10.1016/S0140$\underline{\text { 6736(07)60153-6 }}$

7. Rosengart AJ, Schultheiss KE, Tolentino J, Macdonald RL. Prognostic factors for outcome in patients with aneurysmal subarachnoid hemorrhage. Stroke 2007;38(8):2315-2321.

https://doi.org/10.1161/ $\underline{\text { STROKEAHA.107.484360 }}$ 
8. Perry JJ, Sivilotti ML, Sutherland $J$ et al.Validation of the Ottawa Subarachnoid Hemorrhage Rule in patients with acute headache. Can Med Assoc J 2017;189(45):e1379-1385. https://doi.org/10.1503/cmaj.170072

9. Bechan RS, Van Rooij SB, Sprengers $\mathrm{ME}$ et al. CT angiography versus 3D rotational angiography in patients with subarachnoid hemorrhage. Neuroradiology 2015;57(12):1239-1246. https://doi.org/10.1007/s00234-015$\underline{1590-9}$

10. Devkota UP, Aryal KR. Result of surgery for ruptured intracranial aneurysms in Nepal. Br J Neurosurg 2001;15(1):13-16.

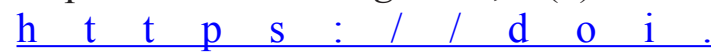
org/10.1080/02688690020024328

11. JagadeesanBD, Almandoz JE, Kadkhodayan $\mathrm{Y}$ et al. Size and anatomic location of ruptured intracranial aneurysms in patients with single and multiple aneurysms: a retrospective study from a single center. J Neurointerv Surg 2014;6(3):169-174. ht tps://doi.org/10.1136/ neurintsurg-2012-010623

12. Kassell NF, Torner JC. Size of Intracranial Aneurysms. Neurosurgery 1983;12(3):291-297. https://doi.org/10.1227/00006123$\underline{198303000-00007}$

13. Korja M, Kivisaari R, RezaiJahromi B, Lehto H. Size and location of ruptured intracranial aneurysms: consecutive series of 1993 hospital-admitted patients. $J \quad$ Neurosurg 2016;127(4):748-753.

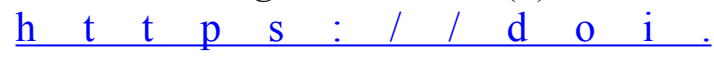
org/10.3171/2016.9.JNS161085

14. Kaminogo M, Yonekura M, Shibata $\mathrm{S}$. Incidence and outcome of multiple intracranial aneurysms in a defined population. Stroke 2003;34(1):16-21. https://doi.org/10.1161/01. $\underline{\text { STR.0000046763.48330.AD }}$ 